\title{
Simulations of $\mathrm{Si}$ and $\mathrm{SiO}_{2}$ Etching in $\mathrm{SF}_{6}+\mathrm{O}_{2}$ Plasma
}

\author{
R. KNIZIKEVIČIUS* \\ Department of Physics, Kaunas University of Technology, 73 K. Donelaičio St., LT-44029 Kaunas, Lithuania
}

(Received July 4, 2008; revised version November 23, 2009; in final form December 1, 2009)

\begin{abstract}
The plasma chemical etching of $\mathrm{Si}$ and $\mathrm{SiO}_{2}$ in $\mathrm{SF}_{6}+\mathrm{O}_{2}$ plasma is considered. The concentrations of plasma components are calculated by fitting the experimental data. The derived concentrations of plasma components are used for the calculation of $\mathrm{Si}$ and $\mathrm{SiO}_{2}$ etching rates. It is found that the reaction probabilities of $\mathrm{F}$ atoms with $\mathrm{Si}$ atoms and $\mathrm{SiO}_{2}$ molecules are equal to $\varepsilon=(8.75 \pm 0.41) \times 10^{-3}$ and $\varepsilon=(7.18 \pm 0.45) \times 10^{-5}$, respectively. The influence of $\mathrm{O}_{2}$ addition to $\mathrm{SF}_{6}$ plasma on the etching rate of $\mathrm{Si}$ is determined.
\end{abstract}

PACS numbers: 52.77.Bn, 81.65.Rv

\section{Introduction}

Trenches with smooth surfaces and round corners are required for device isolation, formation of vertical capacitors in integrated circuits and waveguides in optoelectronics. It prevents voids during trench refilling and avoids breakdown of dielectric film covering the trench sidewalls. Round corners reduce the build-up of mechanical stress onto a silicon surface. $\mathrm{SF}_{6}+\mathrm{O}_{2}$ plasma is commonly used in the high aspect ratio structure applications because of the high etching rate of silicon [1-4]. High etching anisotropy is achieved using sidewall passivation with $\mathrm{SiO}_{2}$ molecules. In experiment [5], it was shown that the number of fluorine atoms per silicon in the $\mathrm{SiO}_{x} \mathrm{~F}_{y}$ layer passivating the sidewalls decreases from 2.0 for pure $\mathrm{SF}_{6}$ to 1.0 at $50 \% \mathrm{O}_{2}$ content in the feed, and the number of oxygen atoms per silicon increases from 0 for pure $\mathrm{SF}_{6}$ to 1.7 at $50 \% \mathrm{O}_{2}$. The thickness of the $\mathrm{SiO}_{x} \mathrm{~F}_{y}$ layer monotonically increases with the increase of $\mathrm{O}_{2}$ content in the feed. At the trench bottom the $\mathrm{SiO}_{x} \mathrm{~F}_{y}$ layer is very thin due to intensive ion bombardment.

Numerical simulations of plasma processing are useful in many ways [6]. An improved understanding of a plasma processing system is achieved by comparing predictions from numerical simulations with experimental observations. The optimisation of existing processes follows such an understanding. Simulations based on reliable physical/chemical modelling of a plasma processing system significantly reduce the number of associated experiments that otherwise would have to be performed. Additionally, such simulations are used in the computer-aided design to optimise manufacturing processes.

In this work, the main reactions occurring in a $\mathrm{SF}_{6}+\mathrm{O}_{2}$ plasma are considered. The concentrations of plasma components are calculated by fitting the experimental data. Using the derived concentrations of plasma components, plasma chemical etching $(\mathrm{PCE})$ of $\mathrm{Si}$ and $\mathrm{SiO}_{2}$ is investigated. The values of reaction rate constants and desorption frequencies, obtained from analysis of PCE of

* e-mail: Rimantas.Knizikevicius@ktu.lt
Si and $\mathrm{SiO}_{2}$, are used for the calculation of the reaction probabilities.

\section{Model}

\subsection{Plasma composition}

The composition of $\mathrm{SF}_{6}+\mathrm{O}_{2}$ plasma is considered. Specific reactions in $\mathrm{SF}_{6}+\mathrm{O}_{2}$ plasma are oxidation reactions of $\mathrm{SF}_{x}(x \leq 5)$ radicals. $\mathrm{SOF}_{4}$ molecules are an initial oxidation product found in the exhaust by mass spectrometry [7]. In Table I, the homogeneous reactions, taking place in $\mathrm{SF}_{6}+\mathrm{O}_{2}$ plasma, in a general case are presented. In order to make the simulation computationally tractable, only the main reactions are included in the model:

$$
\begin{aligned}
& \mathrm{SF}_{6}+\mathrm{e} \rightarrow \mathrm{SF}_{5}+\mathrm{F}+\mathrm{e}, \\
& \mathrm{O}_{2}+\mathrm{e} \rightarrow 2 \mathrm{O}+\mathrm{e}, \\
& \mathrm{SF}_{5}+\mathrm{O} \rightarrow \mathrm{SOF}_{4}+\mathrm{F}, \\
& \mathrm{SF}_{5}+\mathrm{F}+\mathrm{M} \rightarrow \mathrm{SF}_{6}+\mathrm{M}, \\
& 2 \mathrm{~F}+\mathrm{M} \rightarrow \mathrm{F}_{2}+\mathrm{M}, \\
& 2 \mathrm{O}+\mathrm{M} \rightarrow \mathrm{O}_{2}+\mathrm{M} .
\end{aligned}
$$

These processes are characterized by reaction frequencies for dissociation of $i$-th component of gas mixture $G_{i}$ and reaction for $i$-th with $j$-th type species $R_{i j}$ :

$$
\begin{aligned}
& G_{1}=g_{1}[\mathrm{e}] / N, \\
& G_{6}=g_{6}[\mathrm{e}] / N, \\
& R_{27}=k_{27}, \\
& R_{25}=k_{25}[\mathrm{M}] / N, \\
& R_{55}=k_{55}[\mathrm{M}] / N, \\
& R_{77}=k_{77}[\mathrm{M}] / N,
\end{aligned}
$$

where $g_{i}$ is the dissociation rate constant of $i$-th component of gas mixture, $N$ is the total neutral particle concentration in the plasma, $k_{i j}$ is the reaction rate constant for $i$-th with $j$-th type species, and $\mathrm{M}$ is a third particle or the reactor wall. The ionisation degree of radio frequency plasma does not exceed $2 \%$. All neutral 
components of the plasma are pumped out from the reactor with the same exhaust frequency $E$ at a fixed $\mathrm{O}_{2}$ content in the feed.

TABLE I

List of the standard state reaction enthalpies [8].

\begin{tabular}{c|c}
\hline \hline Reaction & $\Delta_{\mathrm{f}} H_{\text {gas }}^{0}[\mathrm{~kJ} / \mathrm{mol}]$ \\
\hline $\mathrm{SF}_{6}+\mathrm{e} \leftrightarrow \mathrm{SF}_{5}+\mathrm{F}+\mathrm{e}$ & 391.41 \\
$\mathrm{SF}_{5}+\mathrm{e} \leftrightarrow \mathrm{SF}_{4}+\mathrm{F}+\mathrm{e}$ & 224.68 \\
$\mathrm{SF}_{4}+\mathrm{e} \leftrightarrow \mathrm{SF}_{3}+\mathrm{F}+\mathrm{e}$ & 339.52 \\
$\mathrm{SF}_{3}+\mathrm{e} \leftrightarrow \mathrm{SF}_{2}+\mathrm{F}+\mathrm{e}$ & 285.77 \\
$2 \mathrm{SF}_{5}+\mathrm{M} \leftrightarrow \mathrm{S}_{2} \mathrm{~F}_{10}+\mathrm{M}$ & -247.49 \\
$\mathrm{SF}_{5}+\mathrm{O}_{2} \rightarrow \mathrm{SO}_{2} \mathrm{~F}_{2}+3 \mathrm{~F}$ & 388.06 \\
$\mathrm{SF}_{5}+\mathrm{O}_{2} \rightarrow \mathrm{SO}_{2} \mathrm{~F}_{2}+\mathrm{F}_{2}+\mathrm{F}$ & 229.28 \\
$\mathrm{SF}_{4}+\mathrm{O}_{2} \rightarrow \mathrm{SO}_{2} \mathrm{~F}_{2}+2 \mathrm{~F}$ & 163.38 \\
$\mathrm{SF}_{4}+\mathrm{O}_{2} \rightarrow \mathrm{SO}_{2} \mathrm{~F}_{2}+\mathrm{F}$ & 4.60 \\
$\mathrm{SF}_{3}+\mathrm{O}_{2} \rightarrow \mathrm{SO}_{2} \mathrm{~F}_{2}+\mathrm{F}$ & -176.14 \\
$\mathrm{SF}_{2}+\mathrm{O}_{2}+\mathrm{M} \rightarrow \mathrm{SO}_{2} \mathrm{~F}_{2}+\mathrm{M}$ & -461.91 \\
$\mathrm{SF}_{5}+\mathrm{O} \rightarrow \mathrm{SOF}_{2}+3 \mathrm{~F}$ & 353.52 \\
$\mathrm{SF}_{5}+\mathrm{O} \rightarrow \mathrm{SOF}_{2}+\mathrm{F}_{2}+\mathrm{F}$ & 194.74 \\
$\mathrm{SF}_{4}+\mathrm{O} \rightarrow \mathrm{SOF}_{2}+2 \mathrm{~F}$ & 128.84 \\
$\mathrm{SF}_{4}+\mathrm{O} \rightarrow \mathrm{SOF}_{2}+\mathrm{F}_{2}$ & -29.94 \\
$\mathrm{SF}_{3}+\mathrm{O} \rightarrow \mathrm{SOF}_{2}+\mathrm{F}$ & -210.68 \\
$\mathrm{SF}_{2}+\mathrm{O}+\mathrm{M} \rightarrow \mathrm{SOF}_{2}+\mathrm{M}$ & -496.45 \\
$\mathrm{SOF}_{2}+\mathrm{O}+\mathrm{M} \rightarrow \mathrm{SO}_{2} \mathrm{~F}_{2}+\mathrm{M}$ & -463.82 \\
$2 \mathrm{~F}+\mathrm{M} \leftrightarrow \mathrm{F}_{2}+\mathrm{M}$ & -158.78 \\
$\mathrm{O}$ & 498.36 \\
$\mathrm{O}+\mathrm{F}+\mathrm{M} \rightarrow \mathrm{OF}_{2} \mathrm{M}$ & -219.79 \\
$\mathrm{OF}+\mathrm{O} \rightarrow \mathrm{O}_{2}+\mathrm{F}$ & -278.57 \\
$2 \mathrm{OF} \rightarrow \mathrm{O}_{2}+2 \mathrm{~F}$ & -58.78 \\
&
\end{tabular}

Seven neutral chemical species exist in the plasma: $\mathrm{SF}_{6}, \mathrm{SF}_{5}, \mathrm{SOF}_{4}, \mathrm{~F}_{2}, \mathrm{~F}, \mathrm{O}_{2}$, and $\mathrm{O}$ with mole fractions $n_{1}=\left[\mathrm{SF}_{6}\right] / N, n_{2}=\left[\mathrm{SF}_{5}\right] / N, n_{3}=\left[\mathrm{SOF}_{4}\right] / N$, $n_{4}=\left[\mathrm{F}_{2}\right] / N, n_{5}=[\mathrm{F}] / N, n_{6}=\left[\mathrm{O}_{2}\right] / N$, and $n_{7}=$ $[\mathrm{O}] / N$, respectively. The following system of equations includes rate expressions of processes mentioned earlier and describes the kinetics of component concentrations in $\mathrm{SF}_{6}+\mathrm{O}_{2}$ plasma:

$$
\left\{\begin{aligned}
\frac{\mathrm{d} n_{1}}{\mathrm{~d} t}= & I_{1}-G_{1} n_{1}+R_{25} n_{2} n_{5}-E n_{1}, \\
\frac{\mathrm{d} n_{2}}{\mathrm{~d} t}= & G_{1} n_{1}-R_{25} n_{2} n_{5}-R_{27} n_{2} n_{7}-E n_{2}, \\
\frac{\mathrm{d} n_{3}}{\mathrm{~d} t}= & R_{27} n_{2} n_{7}-E n_{3}, \\
\frac{\mathrm{d} n_{4}}{\mathrm{~d} t}= & R_{55} n_{5}^{2}-E n_{4}, \\
\frac{\mathrm{d} n_{5}}{\mathrm{~d} t}= & G_{1} n_{1}-R_{25} n_{2} n_{5}+R_{27} n_{2} n_{7} \\
& -2 R_{55} n_{5}^{2}-E n_{5}, \\
\frac{\mathrm{d} n_{6}}{\mathrm{~d} t}= & I_{6}-G_{6} n_{6}+R_{77} n_{7}^{2}-E n_{6}, \\
\frac{\mathrm{d} n_{7}}{\mathrm{~d} t}= & 2 G_{6} n_{6}-R_{27} n_{2} n_{7}-2 R_{77} n_{7}^{2}-E n_{7},
\end{aligned}\right.
$$

where $I_{i}=\Phi_{i} /\left(V_{0} N\right)$ is the injection rate of $i$-th component of gas mixture, $\Phi_{i}$ is the flow rate of the $i$-th component, and $V_{0}$ is the reactor volume.

\section{2. $\mathrm{SiO}_{2}$ etching}

The PCE of a quartz substrate in a $\mathrm{SF}_{6}+\mathrm{O}_{2}$ plasma is considered. During $\mathrm{PCE}$ of $\mathrm{SiO}_{2}$ in $\mathrm{SF}_{6}+\mathrm{O}_{2}$ plasma, fluorination reactions take place [7]. $\mathrm{F}$ atoms from the plasma react with $\mathrm{SiO}_{2}$ molecules:

$$
\mathrm{SiO}_{2}+4 \mathrm{~F} \rightarrow \mathrm{SiF}_{4}+\mathrm{O}_{2} .
$$

This process is characterized by reaction rate constant $k_{3}$. $\mathrm{SiF}_{4}$ molecules present in the adsorbed layer desorb. The desorption frequency is equal to

$$
\omega=\nu_{0} \exp \left(-E_{\mathrm{d}} / k T\right),
$$

where $\nu_{0}$ is the frequency of oscillation of atoms in the solid, $E_{\mathrm{d}}$ is the desorption activation energy, $k$ is the Boltzmann constant, and $T$ is the temperature. Let us assume that $\mathrm{O}_{2}$ molecules formed instantly desorb.

$\mathrm{SiF}_{4}$ molecules, produced during reaction on the surface, are included in the adsorbed layer of one-monolayer thickness. The mole fraction of $\mathrm{SiF}_{4}$ molecules is equal to $c=\left[\mathrm{SiF}_{4}\right] / C$, where $C$ is the concentration of surface molecules $\left(C=8.90 \times 10^{18} \mathrm{~m}^{-2}\right)$. The following equation includes rate expressions of processes mentioned earlier and describes the kinetics of concentration of $\mathrm{SiF}_{4}$ molecules in the adsorbed layer:

$$
\frac{\mathrm{d} c}{\mathrm{~d} t}=\beta k_{3} n_{5}^{4}-\omega c,
$$

where $\beta=1-\Theta$ is the fraction of the surface not covered with adsorbate, $\Theta=c$ is the surface coverage. Although the fourth power of $n_{5}$ in Eq. (6), and similar equations below, do not correspond to an elementary reaction step [9-12], the fitting procedure using this expression described well the experimentally observed dependence of Si etching rate on $\mathrm{O}_{2}$ content in the feed. It is due to the presence of the $\mathrm{SiO}_{x} \mathrm{~F}_{y}$ layer during $\mathrm{Si}$ and $\mathrm{SiO}_{2}$ etching in $\mathrm{SF}_{6}+\mathrm{O}_{2}$ plasma $[5,13]$. The steady-state concentration of $\mathrm{SiF}_{4}$ molecules is equal to

$$
c_{\mathrm{st}}=\frac{R_{3}}{R_{3}+\omega},
$$

where $R_{3}=k_{3} n_{5}^{4}$ is the reaction frequency. The etching rate is proportional to the desorption rate of formed $\mathrm{SiF}_{4}$ molecules. The steady-state etching rate is equal to

$$
V_{\mathrm{st}}=h_{0} \omega c_{\mathrm{st}}=\frac{h_{0} R_{3} \omega}{R_{3}+\omega},
$$

where $h_{0}=3.35 \AA$ is the thickness of a monolayer.

\subsection{Si etching}

During PCE of $\mathrm{Si}$ in $\mathrm{SF}_{6}+\mathrm{O}_{2}$ plasma, competition between $\mathrm{F}$ and $\mathrm{O}$ atoms for active $\mathrm{Si}$ surface sites takes place $[4,5,7]$. The PCE of a $\operatorname{Si}(111)$ substrate in a plasma is considered. The PCE does not proceed by continuous removal of the outermost $\mathrm{Si}$ layer, but by the formation of a fairly thick, disordered intermediate phase containing $\mathrm{SiF}, \mathrm{SiF}_{2}$, and $\mathrm{SiF}_{3}$ species. Under certain conditions, the trapped $\mathrm{SiF}_{4}$ molecules were also observed [14]. During $\mathrm{PCE}$ of $\mathrm{Si}$ in $\mathrm{SF}_{6}+\mathrm{O}_{2}$ plasma, competition between 
$\mathrm{F}$ atoms and $\mathrm{O}$ atoms for active $\mathrm{Si}$ surface sites takes place $[4,5,7]$. The reactions included in the model are the following:

$$
\begin{aligned}
& \mathrm{Si}+4 \mathrm{~F} \rightarrow \mathrm{SiF}_{4}, \\
& \mathrm{Si}+2 \mathrm{O} \rightarrow \mathrm{SiO}_{2}, \\
& \mathrm{SiO}_{2}+4 \mathrm{~F} \rightarrow \mathrm{SiF}_{4}+\mathrm{O}_{2} .
\end{aligned}
$$

These processes are characterized by reaction rate constants $k_{1}, k_{2}$, and $k_{3}$, respectively. $\mathrm{SiF}_{4}$ molecules present in the adsorbed layer desorb. The desorption frequency is described by Eq. (5). Let us assume that $\mathrm{O}_{2}$ molecules formed instantly desorb.

$\mathrm{SiF}_{4}$ molecules, produced during reactions on the surface, are included in the adsorbed layer of one-monolayer thickness. The mole fraction of $\mathrm{SiF}_{4}$ molecules is equal to $c_{1}=\left[\mathrm{SiF}_{4}\right] / C$, where $C$ is the concentration of surface atoms $\left(C=1.36 \times 10^{19} \mathrm{~m}^{-2}\right)$. Si atoms and $\mathrm{SiO}_{2}$ molecules exist on the surface with mole fractions $c_{2}=[\mathrm{Si}] / C$ and $c_{3}=\left[\mathrm{SiO}_{2}\right] / C$. The mole fractions of surface components must fulfill the condition $c_{2}+c_{3}=1$. The following system of equations includes rate expressions of processes mentioned earlier and describes the kinetics of component concentrations in the adsorbed layer and on the surface:

$$
\left\{\begin{array}{l}
\frac{\mathrm{d} c_{1}}{\mathrm{~d} t}=k_{1} \beta c_{2} n_{5}^{4}+k_{3} \beta c_{3} n_{5}^{4}-\omega c_{1}, \\
\frac{\mathrm{d} c_{2}}{\mathrm{~d} t}=-k_{2} \beta c_{2} n_{7}^{2}+k_{3} \beta c_{3} n_{5}^{4} .
\end{array}\right.
$$

The steady-state concentrations of components are equal to

$$
\begin{aligned}
c_{1, \mathrm{st}} & =\frac{R_{3}\left(R_{1}+R_{2}\right)}{R_{3}\left(R_{1}+R_{2}\right)+\omega_{1}\left(R_{2}+R_{3}\right)}, \\
c_{2, \mathrm{st}} & =\frac{R_{3}}{R_{2}+R_{3}}, \\
c_{3, \mathrm{st}} & =\frac{R_{2}}{R_{2}+R_{3}},
\end{aligned}
$$

where $R_{1}=k_{1} n_{5}^{4}, R_{2}=k_{2} n_{7}^{2}$, and $R_{3}=k_{3} n_{5}^{4}$ are the reaction frequencies. The etching rate is proportional to the desorption rate of formed $\mathrm{SiF}_{4}$ molecules. The steady-state etching rate is equal to

$$
V_{\mathrm{st}}=h_{0} \omega c_{1, \mathrm{st}}=\frac{h_{0} R_{3} \omega\left(R_{1}+R_{2}\right)}{R_{3}\left(R_{1}+R_{2}\right)+\omega_{1}\left(R_{2}+R_{3}\right)},
$$

where $h_{0}=2.72 \AA$ is the thickness of a monolayer.

\section{Results and discussion}

\subsection{Plasma composition}

Determination of the composition of plasma is important in plasma science and engineering since the composition determines the nature of the physical and chemical processes that can occur. In addition, analysis of the products of the reaction is important to determine the effectiveness of a particular process. The fitting of experimental results is used for the calculation of composition of a $\mathrm{SF}_{6}+\mathrm{O}_{2}$ plasma. The conditions during experiment [7] were the following: the reactor volume $1.0 \times 10^{-4} \mathrm{~m}^{3}$, the flow rate $27 \mathrm{sccm}$, the pressure $133 \mathrm{~Pa}$. Assuming a

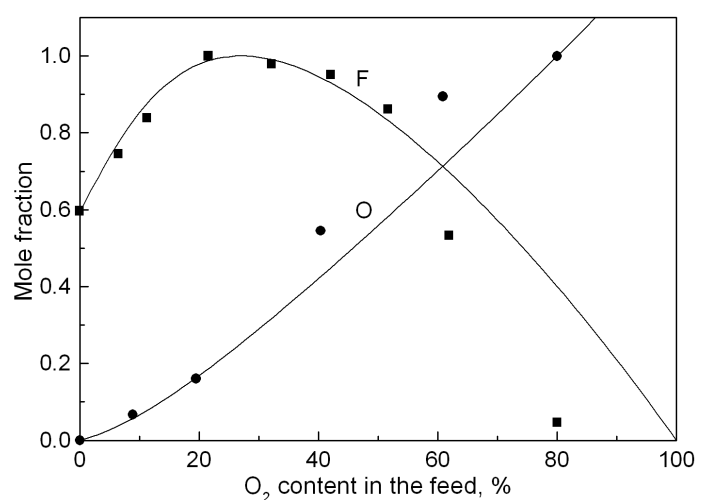

Fig. 1. Experimental [7] (points) and theoretical (curves) dependences of the mole fractions of $\mathrm{F}$ and $\mathrm{O}$ atoms on $\mathrm{O}_{2}$ content in the feed.

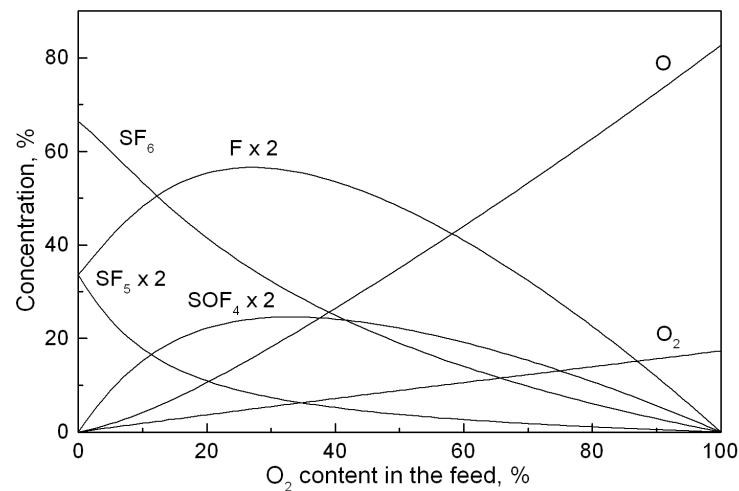

Fig. 2. The dependences of the concentrations of $\mathrm{SF}_{6}+\mathrm{O}_{2}$ plasma components on $\mathrm{O}_{2}$ content in the feed.

plasma temperature of $500 \mathrm{~K}$, the total neutral particle concentration $N=1.93 \times 10^{22} \mathrm{~m}^{-3}$ and the total gas injection rate $I=4.92 \mathrm{~s}^{-1}$ are estimated. The total gas injection rate is estimated using expression $I=\Phi /\left(V_{0} N\right)$, where the flow rate is measured in molecules $\mathrm{s}^{-1}$. Experimental [7] and theoretical dependences of the mole fractions of $\mathrm{F}$ and $\mathrm{O}$ atoms in the plasma on $\mathrm{O}_{2}$ content in the feed at the steady-state regime are shown in Fig. 1. The following values of reaction frequencies are found by fitting: $G_{1}=10 \mathrm{~s}^{-1}, G_{6}=20 \mathrm{~s}^{-1}, R_{25}=200 \mathrm{~s}^{-1}$, $R_{27}=130 \mathrm{~s}^{-1}, R_{55}=R_{77}=0 \mathrm{~s}^{-1}$. It is observed that the values of reaction frequencies $R_{55}$ and $R_{77}$ are very small and can be taken equal to zero. This confirms an assumption that in an alumina reactor, the reaction defined by Eq. (1.5) does not take place [7]. Taking this into account, one may assert that in an alumina reactor, the reaction defined by Eq. (1.6) does not take place as well.

The chemical composition of $\mathrm{SF}_{6}+\mathrm{O}_{2}$ plasma as a function of $\mathrm{O}_{2}$ content in the feed, calculated using Eq. (3), at the steady-state regime is shown in Fig. 2. As $\mathrm{O}_{2}$ content in the feed increases, the concentration of $\mathrm{F}$ atoms initially increases due to the reaction of $\mathrm{O}$ atoms 
with $\mathrm{SF}_{5}$ radicals (Eq. (1.3)). At $27 \% \mathrm{O}_{2}$, the concentration of $\mathrm{F}$ atoms approaches the maximum value. At this point, almost all $\mathrm{SF}_{5}$ radicals in $\mathrm{SF}_{6}+\mathrm{O}_{2}$ plasma have reacted. Subsequently, the concentration starts to decrease in proportion to the amount of injected $\mathrm{SF}_{6}$ molecules.

The conversion of the $i$-th component of the gas mixture indicates a part of molecules converted to reaction products and is equal to

$$
\eta_{i}=1-E n_{i} / I_{i} \text {. }
$$

The dependences of the conversion of $\mathrm{SF}_{6}$ and $\mathrm{O}_{2}$ molecules on $\mathrm{O}_{2}$ content in the feed at different flow rates are shown in Fig. 3. The part of converted molecules increases with the decrease of the flow rate. The increase of the conversion of $\mathrm{SF}_{6}$ molecules is related to the reaction of $\mathrm{O}$ atoms with $\mathrm{SF}_{5}$ radicals.

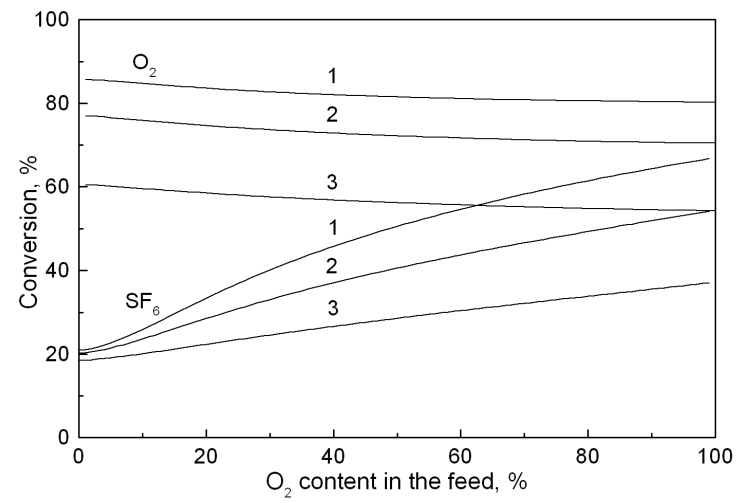

Fig. 3. The dependences of the conversion of $\mathrm{SF}_{6}$ and $\mathrm{O}_{2}$ molecules on $\mathrm{O}_{2}$ content in the feed at different flow rates $\Phi$ (in sccm): $1-15,2-27$, and $3-60$.

\section{2. $\mathrm{SiO}_{2}$ etching}

Six primary processes occur during a plasma etching: (1) generation of reactive species, (2) diffusion to surface, (3) adsorption, (4) reaction, both chemical and physical (such as sputtering), (5) desorption, and (6) diffusion into bulk gas. If any of them does not occur, the entire processing stops. The mole fractions of plasma components calculated from the previous model of plasma composition are used for the calculation of $\mathrm{SiO}_{2}$ etching rate. Experimental [7] and theoretical dependences of $\mathrm{SiO}_{2}$ etching rate on $\mathrm{O}_{2}$ content in the feed are shown in Fig. 4. The following values of reaction rate constant and desorption frequency are found by fitting: $k_{3}=7.0 \times 10^{4} \mathrm{~s}^{-1}$, $\omega=28 \mathrm{~s}^{-1}$. The $\mathrm{SiO}_{2}$ etching rate at high $\mathrm{O}_{2}$ content is suppressed due to the decreased generation of $\mathrm{F}$ atoms. Let us investigate the etching of a $\mathrm{SiO}_{2}$ substrate in the ambience of $\mathrm{F}$ atoms at room temperature. According to de l'Hôpital's rule, the maximum etching rate is expressed as

$$
V_{\max }=h_{0} \omega \text {. }
$$

It is observed that maximum etching rate depends only on the desorption frequency. The ratio $V / V_{\max }$ is equal to

$$
\frac{V}{V_{\max }}=\frac{1}{1+\omega / R_{3}} .
$$

The dependence of $\mathrm{SiO}_{2}$ etching rate on the flux of $\mathrm{F}$ atoms is shown in Fig. 5. In the range of $(0.47-2.05) \times$ $10^{24} \mathrm{~m}^{-2} \mathrm{~s}^{-1}$, the etching rate almost linearly depends on the flux of $\mathrm{F}$ atoms. The dependence of etching rate on the flux of $\mathrm{F}$ atoms is fitted line and the reaction probability $\varepsilon=\Phi_{2} / 4 \Phi_{1}$, where $\Phi_{1}$ is the flux of $\mathrm{F}$ atoms to the surface and $\Phi_{2}$ is the flux of $\mathrm{SiF}_{4}$ molecules from the surface, is calculated. The obtained value of reaction probability is equal to $\varepsilon=(7.18 \pm 0.45) \times 10^{-5}$. Similar value of reaction probability is measured experimentally [9]. In this experiment it was found that the reaction probability at room temperature is equal to $(3.0 \pm 0.3) \times 10^{-5}$. The reaction probability depends on the substrate temperature [9] and the extent of surface contamination [15].

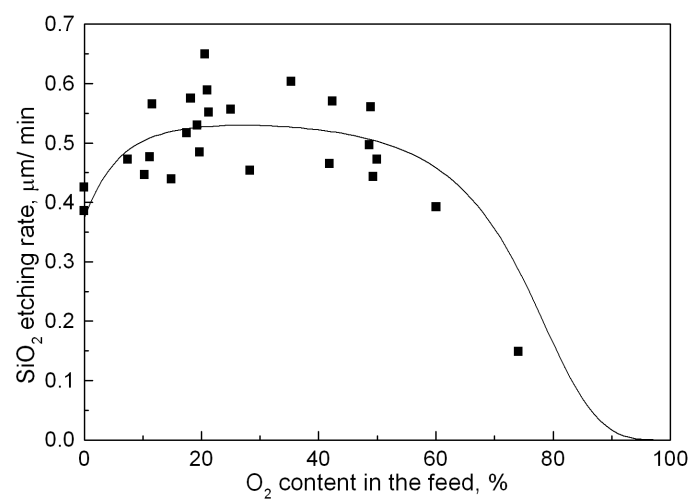

Fig. 4. Experimental [7] (points) and theoretical (curve) dependences of $\mathrm{SiO}_{2}$ etching rate on $\mathrm{O}_{2}$ content in the feed.

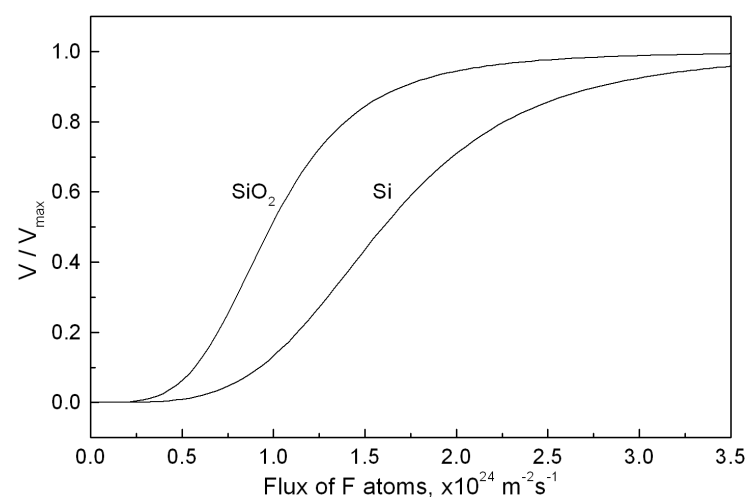

Fig. 5. The dependences of etching rates of $\mathrm{Si}\left(V_{\max }=\right.$ $57 \mu \mathrm{m} / \mathrm{min})$ and $\mathrm{SiO}_{2}\left(V_{\max }=0.56 \mu \mathrm{m} / \mathrm{min}\right)$ on the flux of $\mathrm{F}$ atoms.

\subsection{Si etching}

The mole fractions of plasma components calculated from the previous model of plasma composition are used 
for the calculation of Si etching rate. Experimental [7] and theoretical dependences of $\mathrm{Si}$ etching rate on $\mathrm{O}_{2}$ content in the feed are shown in Fig. 6. The following values of reaction rate constants and desorption frequency are found by fitting: $k_{1}=1.25 \times 10^{6} \mathrm{~s}^{-1}, k_{2}=100 \mathrm{~s}^{-1}$, $k_{3}=1.00 \times 10^{4} \mathrm{~s}^{-1}, \omega=3500 \mathrm{~s}^{-1}$. It is observed that the desorption frequency of $\mathrm{SiF}_{4}$ molecules has different values for $\mathrm{Si}$ and $\mathrm{SiO}_{2}$ etching. During $\mathrm{PCE}$ of $\mathrm{SiO}_{2}$ the desorption frequency of $\mathrm{SiF}_{4}$ molecules is markedly lower than that during $\mathrm{PCE}$ of $\mathrm{Si}$ in $\mathrm{SF}_{6}+\mathrm{O}_{2}$ plasma. As the frequency of oscillation of atoms in the solid $\nu_{0}$ weakly depends on temperature, it follows that the temperature during PCE of Si substrate is higher than the one of $\mathrm{SiO}_{2}$ substrate. According to work [16], the difference between the surface temperatures of $\mathrm{Si}$ and $\mathrm{SiO}_{2}$ substrates is equal to $70 \mathrm{~K}$. The wafer was not in good thermal contact with the substrate holder. The heating of the surface and near-surface layer by the exothermal reactions during $\mathrm{PCE}$ of $\mathrm{Si}$ in $\mathrm{SF}_{6}$ plasma at low temperatures results in the same etched groove profiles as at room temperature [17].

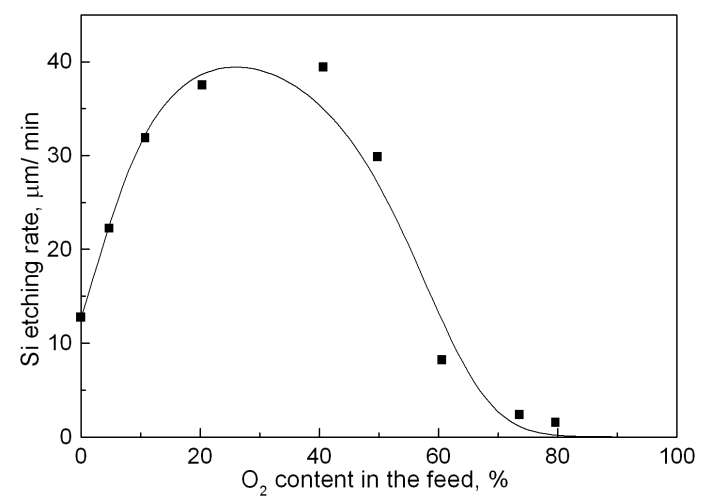

Fig. 6. Experimental [7] (points) and theoretical (curve) dependences of $\mathrm{Si}$ etching rate on $\mathrm{O}_{2}$ content in the feed.

The dependences of the concentrations of the adsorbed layer and surface components on $\mathrm{O}_{2}$ content in the feed, calculated using Eqs. (11.1)-(11.3), are shown in Fig. 7. It is observed that concentration of $\mathrm{SiO}_{2}$ molecules on the surface is low when the maximum etching rate of $\mathrm{Si}$ in $\mathrm{SF}_{6}+\mathrm{O}_{2}$ plasma is achieved. Therefore, the maximum etching rate of $\mathrm{Si}$ is achieved at the same $\mathrm{O}_{2}$ content as the maximum concentration of $\mathrm{F}$ atoms in $\mathrm{SF}_{6}+\mathrm{O}_{2}$ plasma. The dependence of $\mathrm{Si}$ etching rate on the concentration of $\mathrm{F}$ atoms in the plasma is shown in Fig. 8. It is observed that a fixed concentration of $\mathrm{F}$ atoms in the plasma corresponds to two different values of Si etching rates, which depend on $\mathrm{O}_{2}$ content. It is due to the formation of high amount of $\mathrm{SiO}_{2}$ molecules on the surface. As $\mathrm{F}$ atoms react with $\mathrm{SiO}_{2}$ molecules more slowly than with $\mathrm{Si}$ atoms, the etching rate is suppressed at high $\mathrm{O}_{2}$ content in the feed.

Let us investigate the etching of a $\mathrm{Si}(111)$ substrate in the ambience of $\mathrm{F}$ atoms at room temperature. The

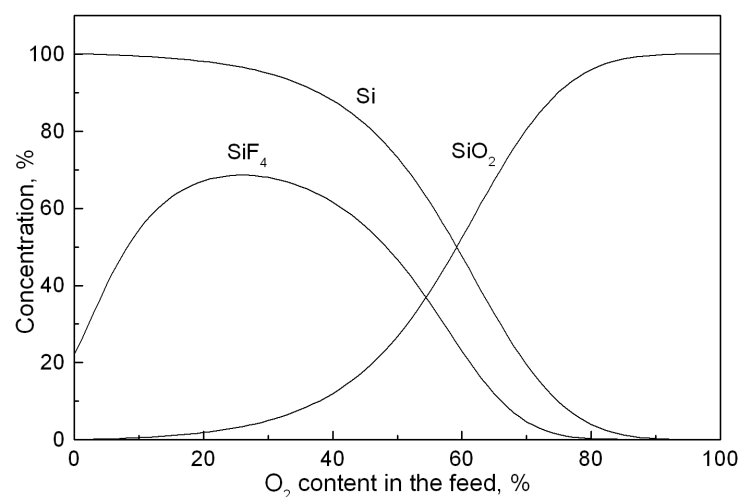

Fig. 7. The dependences of the concentrations of the adsorbed layer and surface components on $\mathrm{O}_{2}$ content in the feed during PCE of $\mathrm{Si}$ in $\mathrm{SF}_{6}+\mathrm{O}_{2}$ plasma.

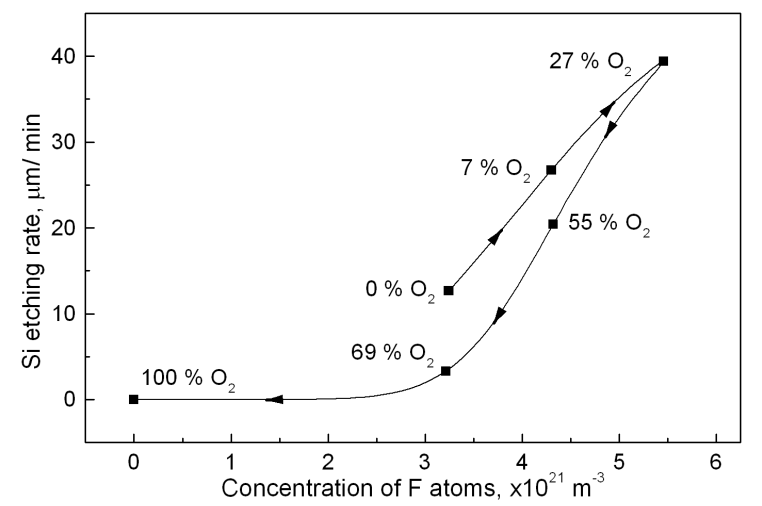

Fig. 8. The dependence of $\mathrm{Si}$ etching rate on the concentration of $\mathrm{F}$ atoms in $\mathrm{SF}_{6}+\mathrm{O}_{2}$ plasma. Arrows indicate the direction of increasing $\mathrm{O}_{2}$ content in the feed.

dependence of $\mathrm{Si}$ etching rate on the flux of $\mathrm{F}$ atoms is shown in Fig. 5. In the range of $(0.76-3.35) \times$ $10^{24} \mathrm{~m}^{-2} \mathrm{~s}^{-1}$, the dependence of etching rate on the flux of $\mathrm{F}$ atoms is fitted line and the reaction probability $\varepsilon$ is calculated. The obtained value of reaction probability is equal to $\varepsilon=(8.75 \pm 0.41) \times 10^{-3}$. Similar values of reaction probability are measured experimentally (Table II). The reaction probability depends on the substrate tem-

TABLE II

The values of reaction probability $\varepsilon$ at room temperature.

\begin{tabular}{c|c|c|c}
\hline \hline Flux $\left[\mathrm{m}^{-2} \mathrm{~s}^{-1}\right]$ & Substrate & $\varepsilon$ & Ref. \\
\hline $2.3 \times 10^{23}-1.1 \times 10^{26}$ & $\mathrm{Si}(100)$ & 0.0017 & {$[10]$} \\
$(2.5-5) \times 10^{18}$ & $\mathrm{Si}(100)$ & 0.083 & {$[18]$} \\
$2.0 \times 10^{22}$ & poly-Si & 0.04 & {$[19]$} \\
$1.6 \times 10^{20}-5.2 \times 10^{22}$ & p-Si(100) & 0.1 & {$[20]$} \\
$4.3 \times 10^{19}$ & poly-Si & 0.06 & {$[21]$} \\
$6.0 \times 10^{20}-4.0 \times 10^{21}$ & p-Si(100) & $0.02-0.1$ & {$[22]$}
\end{tabular}


perature [10], doping [23], and the extent of surface contamination [24].

\section{Conclusions}

1. As $\mathrm{O}_{2}$ content in the feed increases, the concentration of $\mathrm{F}$ atoms initially increases due to the reaction of $\mathrm{O}$ atoms with $\mathrm{SF}_{5}$ radicals. At the maximum concentration of $\mathrm{F}$ atoms, almost all $\mathrm{SF}_{5}$ radicals in $\mathrm{SF}_{6}+\mathrm{O}_{2}$ plasma have reacted. Subsequently, the concentration starts to decrease in proportion to the amount of injected $\mathrm{SF}_{6}$ molecules.

2. The reaction probability for $\mathrm{SiO}_{2}+4 \mathrm{~F} \rightarrow \mathrm{SiF}_{4}+\mathrm{O}_{2}$ is equal to $\varepsilon=(7.18 \pm 0.45) \times 10^{-5}$.

3. The reaction probability for $\mathrm{Si}+4 \mathrm{~F} \rightarrow \mathrm{SiF}_{4}$ is equal to $\varepsilon=(8.75 \pm 0.41) \times 10^{-3}$.

\section{References}

[1] C.P. D'Emic, K.K. Chan, J. Blum, J. Vac. Sci. Technol. B 10, 1105 (1992).

[2] J.W. Bartha, J. Greschner, M. Puech, P. Maquin, Microelectron. Eng. 27, 453 (1995).

[3] M. Boufnichel, S. Aachboun, F. Grangeon, P. Lefaucheux, P. Ranson, J. Vac. Sci. Technol. B 20, 1508 (2002).

[4] S. Gomez, R.J. Belen, M. Kiehlbauch, E.S. Aydil, J. Vac. Sci. Technol. A 22, 606 (2004).

[5] G.S. Oehrlein, K.K. Chan, M.A. Jaso, G.W. Rubloff, J. Vac. Sci. Technol. A 7, 1030 (1989).

[6] S. Hamaguchi, IBM J. Res. Develop. 43, 199 (1999).

[7] R. d'Agostino, D.L. Flamm, J. Appl. Phys. 52, 162 (1981).

[8] M.W. Chase, Jr., NIST-JANAF Thermochemical Tables, J. Phys. Chem. Ref. Data, Monograph 9, 1998 p. 1963.
[9] D.L. Flamm, C.J. Mogab, E.R. Sklaver, J. Appl. Phys. 50, 6211 (1979).

[10] D.L. Flamm, V.M. Donnelly, J.A. Mucha, J. Appl. Phys. 52, 3633 (1981).

[11] G.A. de Wijs, A. de Vita, A. Selloni, Phys. Rev. Lett. 78, 4877 (1997).

[12] R. Knizikevičius, Vacuum 82, 1191 (2008).

[13] J. Feldsien, D. Kim, D.J. Economou, Thin Solid Films 374, 311 (2000).

[14] F.R. McFeely, J.F. Morar, F.J. Himpsel, Surf. Sci. 165, 277 (1986).

[15] J.W. Butterbaugh, D.C. Gray, H.H. Sawin, J. Vac. Sci. Technol. B 9, 1461 (1991).

[16] R. Knizikevičius, Vacuum 68, 29 (2002).

[17] G. Marcos, A. Rhallabi, P. Ranson, J. Vac. Sci. Technol. A 21, 87 (2003).

[18] M.J. Vasile, F.A. Stevie, J. Appl. Phys. 53, 3799 (1982).

[19] Y.H. Lee, M.M. Chen, J. Appl. Phys. 54, 5966 (1983).

[20] K. Ninomiya, K. Suzuki, S. Nishimatsu, O. Okada, J. Appl. Phys. 58, 1177 (1985).

[21] C.B. Mullins, J.W. Coburn, J. Appl. Phys. 76, 7562 (1994).

[22] T. Chevolleau, P.Y. Tessier, C. Cardinaud, G. Turban, J. Vac. Sci. Technol. A 15, 2661 (1997).

[23] J.A. Yarmoff, F.R. McFeely, Phys. Rev. B 38, 2057 (1988).

[24] N. Selamoglu, J.A. Mucha, D.L. Flamm, D.E. Ibbotson, J. Appl. Phys. 62, 1049 (1987). 